Open Access

\title{
Personalisation in educational technology: the absence of underlying pedagogies
}

\author{
Antonio Bartolomé ${ }^{*}$ (D), Linda Castañeda ${ }^{2}$ and Jordi Adell ${ }^{3}$
}

\author{
* Correspondence: \\ abartolome@ub.edu \\ ${ }^{1}$ Institute of Research in Education, \\ Universitat de Barcelona, Pg. Vall \\ d'Hebrón, 171, 08035 Barcelona, \\ Spain \\ Full list of author information is \\ available at the end of the article
}

\begin{abstract}
Personalization is one of the recurring themes in education and has occupied a large amount of specialised literature, since its appearance in the 1960s. A systematic exploration of the literature of the last 55 years (1960-2015) is presented and is intended to analyse which educational perspective underlies the customized environments or experiences proposed in the educational technology that is addressed in the literature. It is important to understand that this analysis is a very relevant challenge, if we want to understand what pedagogical approaches have been continuously developed and how and why we should consider their future. The results show a complete centralisation of experiences in technological developments, the majority of them focussed in Higher Education, as well as a lack of an explicit pedagogical perspective in the experiences analysed, especially those with greater impact. It also shows a shortage of in-house pedagogical material - developed in the light of this research, that evolves and makes an impact on the educational landscape.
\end{abstract}

Keywords: Adaptive learning, Educational technology, Critical perspective, Literature review, Higher education

\section{Introduction}

Personalisation is one of the recurring themes in education in general, and in Higher Education in particular since the beginning of time. The goal of converting the learning (and teaching) experience into a flexible enough process so that it responds to the individual and unique needs of each person, accompanies us almost from the time we ask ourselves questions about how we teach and learn (Chen, 2008).

However, despite expectations generated and reflected in reports on the present and future of educational innovation or the impact of technology on education (Cobo, 2016), specially in Higher Education, as well as the ideals of flexibilisation and educational individualisation do not seem to have materialised either in the last decade, or even in the last 50 years (Martínez, 2001; Selwyn, 2016).

Quite the contrary, despite the recurring interest in the theme and the constancy of academic interest that it arouses (reflected in the constant appearance in the literature specialised in educational technology of the last 50 years), it seems that the results of recent experiments, are at least inconclusive (Pane, Steiner, Baird, Hamilton, \& Pane, 2017). But what is even more worrying is the fact that "pedagogical gaps" are increasingly more evident and recurrent in almost all the literature on personalisation, and related to which

(c) The Author(s). 2018 Open Access This article is distributed under the terms of the Creative Commons Attribution 4.0 International License (http://creativecommons.org/licenses/by/4.0/), which permits unrestricted use, distribution, and reproduction in any medium, provided you give appropriate credit to the original author(s) and the source, provide a link to the Creative Commons license, and indicate if changes were made. 
educational model (with all its nuances) underpins how technology has tried to respond to the differentiation of the teaching-learning processes.

It is important, then, if we want to take a critical view of this phenomenon beyond its theorisation, to explore what the pedagogical nature of personalisation is and has been from the perspective of educational technology. To do this, it is necessary to understand what form does the didactic implementation of personalisation technologies take especially those that appear in the experiences of scientific literature, taking into account that this seems to be specially dedicated to Higher Education, and that support the advances that are being undertaken in this field. Understanding that, without an appropriate view of its nature, it is impossible to build a body of pedagogical knowledge relating to personalisation based only on the scientific knowledge available. This study is dedicated to this specific aspect.

\section{Theoretical framework: personalisation and its relationship with the different key elements of the teaching-learning process}

The concept of personalisation in education is complex and multifaceted. The idea of adapting teaching to the learner can be ascribed to the tradition of pupil-centred pedagogies (Coll, 2016), and to the work of authors as far removed from this tradition as Bloom (1984). In the 1980s, the computer as "tutor" (Taylor, 1980) was one of the visions of the role of educational technology, a vision that survives today, and in the last years, personalisation is presented through the concept of adaptive learning, based on the use of algorithms, data mining and learning analytics (Johnson et al., 2016), which offer "educational services" tailored to consumers' tastes.

Without going into further detail, the US Department of Education defines personalised learning as "...instruction in which the pace of learning and the instructional approach are optimised for the needs of each learner. Learning objectives, instructional approaches, and instructional content (and its sequencing) may all vary based on learner needs. In addition, learning activities are meaningful and relevant to learners, driven by their interests, and often self-initiated." (U.S. Department of Education, 2017, p. 9). That is, personalising learning involves redefining each and every aspect of how the person learns and how the person is taught.

This means that in order to analyse how personalisation has been included in the processes of the implementation of educational technology throughout history, it is necessary to dwell on a holistic perspective that includes many faces of the educational process. Thus, to explore what pedagogical assumptions underlie the design of socalled adaptive learning environments enriched with technology (hereafter TEALEs, its English acronym Technology Enhanced Adaptive Learning Environments, Conole \& Fill, 2005) or similar initiatives, this study has defined four key elements that characterise educational implementation in a general manner (Fig. 1):

epistemological nature psychological approach didactic materialisation technological approach

Fig. 1 Key elements that characterise educational implementation. Source: Own creation 
At the same time, in order to carry out this analysis we have tried to restrict the meaning of each of these elements, unifying the numerous works on the different subjects and creating a really general vision of each one and its possible categories of analysis, and perhaps losing nuances to gain capacity of interpretation, in the following way:

\section{Epistemological perspective:}

The epistemological perspective of educational implementation reflects the "concepts, theories and central problems in the understanding of knowledge and justification" (Audi, 2011, page. xiii) that underlie the proposed designs and implementations. For this analysis, a generic approach according to which there are four main epistemological principles considered: empiricism, rationalism, idealism and constructivism (Audi, 2011). The aim is to see, in each case, what type of knowledge underlies the different approaches to the TEALEs that we find throughout the literature. That is, how knowledge is understood, created, reproduced, improved, transmitted, etc. and if possible, how these systems do or do not intend to contribute to the development of personal epistemologies (Holma \& Hyytinen, 2015).

\section{Psychological approach:}

It seeks to understand how each personalisation proposal comprehends the learning process of the persons concerned (Hung, 2001; Klotz, 1971; Tomei, 2003), in at least two complementary ways:

Firstly, it is necessary to analyse which of the learning theories support the proposal (Driscoll, 2005 \& Ertmer \& Newby, 1993), and which are gathered in the three perspectives that Dede (2008) points out: Objectivism/Behaviourism, Cognitivism/ Pragmatism, and Constructivism/Interpretivism, to which Connectivism (Siemens, 2005) can be added given its relevance in digital learning environments, although it may be doubtful to introduce it as a theory of learning (Verhagen, 2006).

Secondly, it is considered essential to analyse what kind of learnings are those that seek to be enhanced through interventions. In this respect, there are well known approaches, such as the "levels of thought" found in the work of Marzano (2001) on his reviewing of the work of Bloom, Engelgart, Furst, Hill, \& Krathwohl, 1956 (subsequent to Bloom's reviews, there are those of Anderson, 2005; Anderson \& Krathwohl, 2001; Marzano, 1998, 2001; Marzano et al., 1988; Marzano \& Kendall, 2007); or even some connection with the SAMR model of learning of Puentedura (Puentedura, 2012).

However, for the purposes of this research, the types of learning by Illeris (2009) will be adopted, which understands that the different moments and needs of people require a different kind of mental effort and, by their very nature make very diverse contributions and in a way in which the educational processes personally affect them. Thus, it is understood that the intended learning can be:

cumulative, understood as one that seeks the acquisition of new isolated elements that must be remembered and learned to be used in isolated situations (data, an address, a telephone number, a code or password); assimilative, or by addition, which would be the introduction of a new element in a scheme already acquired by the person and that makes the previous scheme more complex, deep or developed (the creation of a formula, greater and better detail on an event, a theory or a procedure); 
accommodative, which implies the substitution of some previous mental pattern for a new way to understand that reality and solve in that way a problem; meaningful (Rogers, 1951) - which Illeris also identifies with the expansive (Engeström, 1987), transitional (Alheit 1994) or the transformational (Mezirow, 1991), understood as involving profound changes in personality, and the beliefs or attitudes of a person.

\section{Didactic materialisation of the implementation}

Understanding what the didactic implementation of personalisation technologies that appear in the experiences in the scientific literature are like involves analysing how the personalisation systems that have been implemented interact with some of the key elements of the teaching-learning process and at the same time how they understand the context in which they are placed.

This research will focus this study on five key elements in the implementation of teaching strategies with technologyz, (Castañeda, 2011):

- the organisation of the groups.

- The modality of the educational process that supports the TEALE.

- the goals underlying the implementation.

- the evaluation of the learning that is carried out (purpose, subject and organisation of the process).

- the role of TEALE in the learning process.

In addition, it is understood that each implementation can understand the educational process as a reality in which its parts maintain concrete relationships, depending on whether the system responds to a reality perceived in one way or another. Thus, for this proposal, we understand that there are basically four types of perceived contexts (the Cynefin framework):

- simple contexts, mastery of good practices, characterised by stability and clear cause-effect relations in which "we know what we know".

- complicated contexts, mastery of experts, characterised by multiple responses, in which "we know what we do not know".

- complex contexts, the domain of emergence, characterised by the fact that the answers cannot be discovered and in which "we do not know what we do not know”.

- chaotic contexts, the domain of rapid response, in which the search for right answers does not make sense, the relations between cause and effect are impossible to determine because they constantly change and there are no manageable patterns, only turbulence, in the realm of the unknowable (Snowden \& Boone, 2007, page 3).

\section{The technological approach}

The multimedia programs for learning are designed based on two fundamental aspects: human-machine interaction or machine reactivity, and the encoding of information; written text, image, sound, audiovisual, etc. 
The presence of visual and audiovisual elements in the TEALE programmes has been largely conditioned by the technology available at the time, making it difficult to approximate this approach in various historical contexts. Therefore, we are going to look at the first aspect: how the machine adapts to each user and reacts in function of their responses. Attention to individual differences has been a sought-after characteristic of TEALE, as it was considered to be one of its most important contributions (Carlson, 1991; Najjar, 1998; Schwier \& Misanchuk, 1993) and a characteristic of a good educational programme (Kemp \& Smellie, 1989). The importance of this point has been maintained over the years (Beethan \& Sharpe, 2007; Conole \& Fill, 2005).

We can find several models of interaction from the point of view of how the subject navigates or how the team reacts (Bartolomé, 1994; Gayeski, 1995). A first classification is found in programmed teaching curricula and teaching machines (Lumsdaine \& Glaser, 1960; Skinner, 1960). There are two basic designs:

- linear (all subjects follow a single path although at different speeds or with a different number of attempts).

- branched (each subject follows a different path according to their responses) (Fry, 1966; Skinner, 1965, 1979).

These same designs are applied to EAO (CAI/CAL) programs (Gillespie, 2002; Hudson, 1984), which later evolve towards ICAI (intelligent computer-assisted instruction) in which it was intended to equip the programs with intelligent decision-taking based on an inference engine and on the user (Duchastel, 1986; Larkin \& Chabay, 1992; Millward, Mazzucchelli, Magoon, \& Moore, 1978; Rickel, 1989).

\section{Objectives and initial hypothesis}

The main objective of this work is to analyse to what extent the scientific literature in educational technology in the last 55 years (1960-2015), related to experiences on adaptive learning and has had an evident impact in the later literature, has made substantive contributions from the point of view of education and has given meaning to it.

This general objective is set out in four specific objectives related to describing and analysing, should they exist:

- Epistemological perspective (theory regarding the nature of knowledge) that underlies the experiences.

- The didactic model (curricular elements and perspective of context) that is developed in them.

- The psychological approach (learning theory and type of learner) that underlies and

- The technological design approach (design of the interaction) with which the adaptive or personalisation process has been developed.

We start from the conviction that the majority of the experiences carried out and the literature of impact concern especially Higher Education (the tacit focus of our study), however, we wanted to open the observation fork so that this hypothesis does not introduce a new bias in this study and further reduce the sample. 
For this purpose, a systematised literature review of a relevant sample (measured by its subsequent editorial impact) of educational experiences published in specialised scientific literature will be carried out, which will be subjected to an observation guide in which these various aspects are explored.

\section{Study}

\section{Methodological design}

The review of systematic literature presented in this paper has followed a procedure in which the 8-step protocol model defined by Okoli and Schabram (2010) has been combined, together with the literature review phases that are presented in the work of McMillan and Schumacher (2010). The mix of these two proposals results in a process that, in addition to providing a logical route for the research, gives us a chronological order that has tried to be followed in the framework of this research and which we summarise in Fig. 2.

\section{Review protocol}

At first, databases such as ACM, Dialnet+, EBSCO, EdlTLib, Emerald, Eric, IEEE, Redinet, Scielo, Science Direct, SCOPUS and WOS were considered. But after a first tentative test of all of them consisting in the search for the same chain, and comparing the results, it was decided to include a review in this work referring to Education \& Information Technology Library (EdlTLib, currently LearnTechLib-The Learning and Technology Library), Web of Science (WOS), and EBSCO Academic Search.

Returning then to the objectives of the research, the study was limited to Englishlanguage documents that generated a greater impact in later references, assuming the exploratory nature of this study and presuming that the data in this language could coincide with the other.

Considering the aim of this study, and after a first brief review of some of the literature of most interest, it was understood that the significance of this work centred around two main topics of interest: educational technology and kinds of individualised learning.

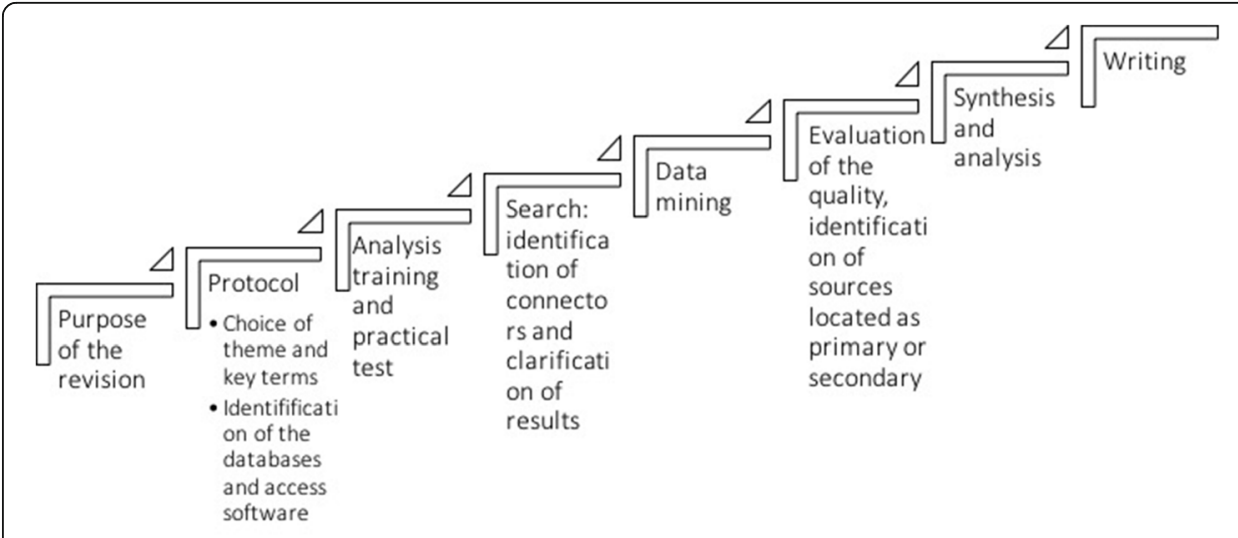

Fig. 2 Procedure of literature review. Source: Adaptation of McMillan \& Schumacher, 2010 and Okoli \& Schabram, 2010. Own preparation 
Although in the first thematic category, the word "technology" solved the proposed needs, in the case of personalisation there was a wide variety of possible terms that could be used and were defined as: "individualised learning", "adaptive learning", "personalised learning", "assisted learning", "personalised teaching" and finally "technology assisted teaching”.

Considering that the search would focus on online databases with search engines that use Boolean descriptors, a decision was taken to organise a search string that included all the afore-mentioned possibilities, thus: "(education OR learning OR instruction) AND (adaptive OR individualized OR personalized) AND technology".

A search was made in the databases with the default chain and was limited to experiences or studies, understanding that these documents include the implementation data that are of interest in this review.

Although all efforts were made to follow the same protocol in all the databases, considering the singularities of some of them and the amount of documentation that could be accessed, there were some peculiarities when trying to include some articles in the filtering process.

After this first scan, a discard was made of the repeated titles and those documents that had a title directly related to other sciences and that did not consider educational aspects were rejected.

Once the search was performed and refined in each database and the results were unified using the same criteria for all the documents gathered, a search of the citations that appeared from each of the documents in the Google Scholar database was undertaken.

After carrying out the planned searches in the corresponding databases, a first pre-production was carried out, in which only the first 5000 articles were considered, which were then divided by decade of publication. After discarding those that did not have citations in Google Scholar, a total search of 1811 articles was obtained, and after the filtering by decade, number of citations and repetitions in the databases in accordance with the selection criteria of the sample laid out in the procedure and considering that from the 1960s, only five of the documents recovered met the search and citation criteria. Table 1 shows the results obtained per decade in each of the databases.

From these results, a sample of the most cited $1 \%$ of each of the decades was chosen, understanding that they were the most influential publications of that time, and deciding that, for reasons of workload and interest in maintaining the representativeness of the various times of publication, a minimum of five articles per decade and a maximum of 15 would be ensured.

Table 1 Results of the search of databases

\begin{tabular}{|c|c|c|c|c|c|c|c|c|c|c|c|c|c|c|c|c|c|c|}
\hline & \multicolumn{3}{|c|}{ 1960-69 } & \multicolumn{3}{|c|}{ 1970-79 } & \multicolumn{3}{|c|}{ 1980-89 } & \multicolumn{3}{|c|}{ 1990-99 } & \multicolumn{3}{|c|}{ 2000-09 } & \multicolumn{3}{|c|}{ 2010-15 } \\
\hline & $\overline{A^{a}}$ & $\mathrm{~B}^{\mathrm{a}}$ & $\mathrm{C}^{\mathrm{a}}$ & $\overline{A^{a}}$ & $\mathrm{~B}^{\mathrm{a}}$ & $\mathbf{C}^{a}$ & $\overline{A^{a}}$ & $\mathrm{~B}^{\mathrm{a}}$ & $\mathbf{C}^{\mathrm{a}}$ & $\overline{A^{a}}$ & $\mathrm{~B}^{\mathrm{a}}$ & $\mathrm{C}^{\mathrm{a}}$ & $\overline{A^{a}}$ & $B^{a}$ & $\mathrm{C}^{\mathrm{a}}$ & $\overline{A^{a}}$ & $\mathrm{~B}^{\mathrm{a}}$ & $\mathbf{C}^{\mathrm{a}}$ \\
\hline EBSCO & 156 & 6 & 5 & 361 & 11 & 10 & 432 & 15 & 14 & 875 & 55 & 32 & 10,386 & 163 & 157 & 5721 & 263 & 239 \\
\hline EdITLib & 0 & 0 & 0 & 0 & 0 & 0 & 0 & 0 & 0 & 99 & 85 & 55 & 730 & 661 & 397 & 426 & 383 & 201 \\
\hline Web of Science & 0 & 0 & 0 & 10 & 6 & 4 & 13 & 4 & 4 & 228 & 52 & 50 & 1511 & 377 & 371 & 1595 & 281 & 272 \\
\hline Total & 5 & & & 14 & & & 18 & & & 137 & & & 925 & & & 712 & & \\
\hline
\end{tabular}

${ }^{a}$ Where $A=$ Articles in first search; $B=$ Articles after the selection in the databases in Google Scholar; $C$ (Data in bold type) $=$ Actual sample 


\section{Analysis protocol}

For the analysis of the documents, it was decided to apply the same protocol of observation that includes:

- General aspects of the document: which included the descriptive data of the analysed document (database where the year of publication appears), key aspects about the nature of the research or experience presented (level, paradigm, scope), geographical location and field of study, and finally, educational level, age of the students involved and curricular area or content (if applicable).

- Basic aspects related to the differentiation of the types of learning, which were defined in four categories of main analysis:

- Epistemological Approach: concept of knowledge that is handled behind the personalisation proposed in the document.

- Didactic Approach: relation with the basic elements of the teaching-learning process (organisation, modality that supports the teaching-learning process, goals, purpose and organisation of evaluation, object of evaluation, and role of the TEALE system in the process) and conception of the educational context.

- Technological Approach: design of the interaction implemented in the experience to which the program basically responds to.

- Psychological approach: questions are included regarding the views on the theory and types of learning that are promoted or supported using underlying TEALEs in the text, either explicitly or implicitly.

In all cases, it was a question of finding not only data but also qualitative evidence that could contribute to the discussion and a deep analysis of the questions that guide this work.

With these elements, a data collection guide was designed that included the categories, limited by closed and exclusive sections (in the form of multiple-choice questions) and a space in which evidence would be required in the form of a citation found in the text for each one of the answers.

The data collection guide was validated by a methodology of an expert panel with the participation of five specialists of renowned prestige and track record in research in the field of educational technology. After the reviews, the guide was composed of 28 closed response items, and 13 open spaces associated with the inclusion of evidence.

\section{Training analysis and practice test}

As indicated above, the same instrument of analysis would be applied to all the documents included in the sample, but it was intended that the documents to be analysed should be divided among the three researchers, so a first test of the application of the instrument was made on two documents for each decade, the same ones for all the researchers, thus harmonising criteria and ensuring comparability of the results.

The first sample of analysis consisted of 47 articles, located in 30 varied sources, which included a total of 11,009 citations in documents located by Google Scholar (1 the least, specifically two articles, one published in 1966 and another in 1968, and 2264 the most, published in 1996) (Table 2). 
Table 2 Initial sample of work: year, source and number of citations in Google Scholar

\begin{tabular}{|c|c|c|}
\hline Year & Source & $\begin{array}{l}\text { Citations in } \\
\text { GScholar }\end{array}$ \\
\hline 1960 & Industrial \& Labor Relations Review & 8 \\
\hline 1966 & Accounting Review & 1 \\
\hline 1967 & Personnel Psychology & 11 \\
\hline 1967 & California Management Review & 5 \\
\hline 1968 & Personnel Psychology & 1 \\
\hline 1971 & Personnel Psychology & 28 \\
\hline 1973 & Journal of Economic Education & 19 \\
\hline 1975 & American Journal of Occupational Therapy & 6 \\
\hline 1975 & Nursing Outlook & 4 \\
\hline 1976 & Accounting Review & 48 \\
\hline 1977 & Journal of Economic Education & 27 \\
\hline 1977 & Teaching Sociology & 10 \\
\hline 1978 & Journal of Educational Psychology & 27 \\
\hline 1978 & Accounting Review & 13 \\
\hline 1980 & Journal of Economic Education & 12 \\
\hline 1981 & Teaching Sociology & 12 \\
\hline 1982 & Journal of Economic Education & 14 \\
\hline 1984 & Journal of Counseling \& Development & 14 \\
\hline 1987 & Professional School Psychology & 17 \\
\hline 1988 & Journal of Economic Education & 16 \\
\hline 1989 & Journal of Economic Education & 71 \\
\hline 1989 & Journal of Economic Education & 38 \\
\hline 1992 & Organization Science & 399 \\
\hline 1994 & Journal of European Industrial Training & 462 \\
\hline 1995 & Mis Quarterly & 515 \\
\hline 1996 & Strategic Management Journal & 2264 \\
\hline 1996 & Journal of Management Information Systems & 266 \\
\hline 1997 & Academy of Management Journal & 712 \\
\hline 1997 & Harvard Business Review & 607 \\
\hline 1997 & Organization Science & 573 \\
\hline 1999 & Etr\&D-Educational Technology Research and Development & 322 \\
\hline 2003 & International Review of Research in Open and Distance Learning & 568 \\
\hline 2003 & Science Education & 319 \\
\hline 2003 & Information Systems Frontiers & 298 \\
\hline 2006 & Academic Medicine & 934 \\
\hline 2008 & International Review of Research in Open and Distance Learning & 321 \\
\hline 2008 & Educational Technology \& Society & 312 \\
\hline 2009 & $\begin{array}{l}\text { World Conference on Educational Multimedia, Hypermedia and } \\
\text { Telecommunications }\end{array}$ & 261 \\
\hline 2010 & Australasian Journal of Educational Technology & 270 \\
\hline 2010 & Computers \& Education & 150 \\
\hline 2010 & International Review of Research in Open and Distance Learning & 128 \\
\hline 2010 & Journal of Educational Psychology & 125 \\
\hline 2010 & Interactive Learning Environments & 116 \\
\hline
\end{tabular}


Table 2 Initial sample of work: year, source and number of citations in Google Scholar (Continued)

\begin{tabular}{lll}
\hline Year Source & $\begin{array}{l}\text { Citations in } \\
\text { GScholar }\end{array}$ \\
\hline 2010 & Computers \& Education & 110 \\
2011 International Review of Research in Open and Distance Learning & 263 \\
2011 International Review of Research in Open and Distance Learning & 202 \\
2012 IEEE Transactions on Learning Technologies & 110 \\
\hline
\end{tabular}

However, once this analysis began, the researchers found that, as a rule, hardly any of the documents included in the sample were likely to respond to the validated test guide. That means that the documents collected in the sample did not include information on any or hardly any of the aspects that were sought to be analysed in this work.

Although some of the conclusions suggested by this first result will be discussed later, a second sampling was carried out on the original sample of 1811 articles, classified by decades of publication and prioritised by the number of citations received in Google Scholar. Of these, a new sample was chosen, consisting of articles that reliably included information from at least three of the categories of specific analyses of this study.

\section{Clarification and data mining}

After the optimised sampling process previously described, a sample of three articles was configured per decade, which we understood to act as an exploratory sample. There was only one exception, the 60s decade, where two of the only ones there met the agreed criteria could be included, for a total of 17 articles, totalling 2490 citations that appeared in Google Scholar and from 14 publications (Table 3).

Table 3 Final sample analysed: decade, year, source and number of citations

\begin{tabular}{llll}
\hline D & Year & Source & Citations in GScholar \\
\hline 1960 & 1967 & California Management & 5 \\
& 1966 & Accounting Review & 1 \\
1970 & 1976 & Accounting Review & 48 \\
& 1971 & Personnel Psychology & 28 \\
& 1977 & Journal of Economic Education & 27 \\
1980 & 1982 & Journal of Economic Education & 14 \\
& 1984 & Journal of Counseling \& Development & 14 \\
& 1981 & Teaching Sociology & 12 \\
1990 & 1992 & Organization Science & 399 \\
& 1994 & American Educational Research Journal & 55 \\
& 1999 & Educational Technology Research and Development & 322 \\
2000 & 2008 & Educational Technology \& Society & 312 \\
& 2003 & Science Education & 319 \\
& 2008 & Educational Technology \& Society & 312 \\
2010 & 2010 & Australasian Journal of Educational Technology & 270 \\
& 2011 & International Review of Research in Open and Distance Learning & 202 \\
& 2010 & Computers \& Education & 150 \\
\hline
\end{tabular}


The articles were analysed one by one with the observation guide, and the most striking data is presented hereafter.

\section{Analysis}

\section{General aspects}

The study analyses 17 reference level articles in relation to the TEALEs. Although the breadth of the sample can not make the data itself representative, as we previously imagined, the vast majority of these publications, refer to higher education experiences (13 of 17).

Since all the research refers to adapting the learning process to individual differences, it is surprising that in seven of them, it is not explicitly defined what is understood by personalised or adaptive or individualised learning. They are studies about a learning model without previously defining it.

When it is defined, the model is interpreted in descriptive terms with reference to how the system interprets the students' responses to provide the most appropriate information.

"computer-tailored interventions provide people with information that is based on their individual characteristics (e.g., their behaviour, attitudes, and perceived barriers), which makes the information personally relevant" (P13 p.1028S)

"The context-aware feature of u-computing environments allows the learning system to better understand the learner's behaviour and the timely environmental parameters in the real world, such as the locations and behaviour of the learner, and the temperature and humidity of the learning environment" (P15 p.83).

\section{Epistemological perspective}

Although it is not always explicitly described, it is possible to see the underlying epistemological perspective reflected. Only in five cases is it not possible to interpret what concept of knowledge is being dealt with behind the issue of personalisation because it is not addressed as the subject of the article.

Of those who approach the matter, we find that the researchers in six of the cases use empirical approaches, like variants such as positivism, neopositivism, realism or "common sense".

In no case does idealism or rationalism seem to support the epistemological thought of texts, but constructivism and social constructivism does (4 cases).

"the social fabric of learning" is supported in important ways through collaboration both in a "community" and on the "network" (P18 p.78)

This happens when adaptive programs are introduced within the framework of a broader training program as a resource for learning, but not as the central axis of learning. The figure of the teacher is especially valued in that case: 
"...the computer-based tutor did not replace the teacher. Rather, it served as a resource that students used in addition to the teacher. Less obviously, but perhaps more importantly, the use of the computer tutor changed the social context of learning in fundamental ways". (P12 p.580)

\section{Psychological approach}

It is possible to determine the psychological theory that is the foundation of this article in all cases except in three of them. Feedback and advice are assumed to affect the behaviour of subjects and the way they acquire knowledge. The machine in these cases adjusts to the stimuli presented until the desired responses (behaviours, learnings) are reached.

"The system automatically will present extra problems to students who needed significant help working the initial problem"... ... "If necessary, extensive remedial routines are available to help students understand the problem and its solution" (P5 p.125)

In six of the cases, the authors refer to constructivism as the base that justifies the design. The reflection acquires noteworthy value in these processes:

"It became a living problem rather than just a cold book" (P p 551)

"individual and socially-mediated reflection are complementary and both are important for helping students learn to reflect" (P11 p.45)

References to Connectivism also exists, although it only occurred in two of the texts:

"Some argue that people's information behaviour should change from receiving information from a few "super nodes" on networks to moving into the information stream themselves and pulling just-in-time information off the networks, perhaps by receiving validation from other users" (P18 p.75)

\section{Didactic materialisation of the implementation}

In five of the cases, it is not possible to interpret accurately the type of learning that is intended. In other cases, we are faced with assimilative learning, perhaps not integrating discrete or isolated elements but establishing more or less complex relationships:

"the current project assumes that students have read the relevant material in a textbook as far as possible, materials avoid dependence on a particular text) and/or listened to a lecture before beginning work on a terminal. Students work homework problems on the terminal, receiving aid from sophisticated diagnostic routines”. (P5 p.125)

Meaningful learning is insisted in three of the articles, in line with the constructivist foundations that defines its psychological approach: 
"effective tools or environments have potential in engaging individual learners in constructive, higher-order, critical thinking about the subjects they are studying" (P16 p.1619)

The mode of teaching that is reflected is mostly blended and, to a lesser extent, distance learning. Only in three of the cases is face-to-face learning spoken about.

Goals are described in terms of specific objectives, and to a lesser extent, by general objectives and competencies. The date of publication of the text is related to the modality chosen to define the goals to be achieved. These goals are related to evidence that will mark the evaluation in four of the occasions, which in turn is perceived as formative as well as accrediting. This seems to be related to the very essence of adaptive or personalised learning, precisely defined as:

"The system automatically will present extra problems to students who needed significant help working on the initial problem. (2) If necessary, extensive remedial routines are available to help students understand the problem and its solution. These routines are of two types. The first, and most common, routine is presented after one or more student responses have indicated that the student does not understand a particular area of the problem. Then the system presents an explanation of the error that the student is making and leads the student to the correct solution, rather than giving him the solution" (P5 p.125)

\section{Technological approach}

Much more attention is paid to the technologies used: in only 3 articles there is no description of them. While in the older articles there are two references to the same PLATO program, in other cases each article refers to specific technologies or tools. Only on two occasions (after 2010) they refer to generic Web 2.0 technologies or those used in MOOCs.

Although other aspects were studied in this research, we will conclude our analysis by emphasising that most of the work is done on linear or branched interaction designs, although in three of the cases we opt for greater control by the student.

Let us conclude by indicating that most of the texts describe studies carried out in the United States, and at university level. There is a predominance of quantitative (60\%) against strictly qualitative research methodology (26.7\%), and is described as comparative studies (41.7\%) and case studies (41.7\%) and, to a lesser extent, experimental studies (16.7\%). Here again, the dominant trends in educational research are detected over the years.

\section{Conclusions}

This study has tried to follow a rigorous review that has taken 2 years for the team of researchers. The exploratory character of the final sample on 17 texts suggests that a study on a larger sample would not provide more significant inputs. Rather, it suggests focusing on the duality present in the most recent studies between two approaches to adaptive learning: one that emphasizes the guidance exercised by an expert system that considers the large amount of information provided by digital equipment, and the other 
which places the student as the decision maker. The teacher happens to have a complementary role in the first case, and facilitator in the second.

Finally, this work turned into an exploratory study on 17 texts that became part of the research on TEALE published between 1960 and 2015. It is true that the sampling system did not provide us with subsequent texts that possibly are currently available, but the explanatory nature of the study should focus on whether to use resources in a similar research on a larger sample based on the results obtained. Moreover, if we also understand that the vast majority of this scientific production based on experiences that has subsequently impacted on other published studies, concerns to higher education.

Endeavouring to respond to the objective set, and ultimately assessing the contributions of the scientific literature on experiences on adaptive learning, we can conclude that it has not made great contributions: based on different psychological theories, as it would seem to follow what the mainstream theory dictates rather than developing an individual line of thought on the subject.

Epistemological thought is relegated in these texts, which focuses more on technological solutions and didactic design, but in most cases, knowledge is understood from an empirical and positivist perspective. Even when it is possible to detect constructivist approaches, they do not necessarily translate to the methodological approach.

In relation to the didactic design, we return to an approximation of the approaches of the research towards dominant tendencies. The same is not true for technological design. Despite the notorious development of technology, design seems anchored in the first linear and branched proposals found in teaching machines and in programmed teaching. Only in the last analysed period, Web 2.0 and the recognition of the importance of competencies such as digital or self-regulated learning seem to generate innovative designs in which the individual takes on a stronger role.

It is somewhat hopeful that the most cited articles of the last two decades and include educational issues in their approaches are those that speak about personalisation based on the choices of the learner and not the machine for the learner, although it is true that this vision could be insignificant because of the type of final sampling used.

However, if there is a result that is particularly striking in this work, it is the one that is revealed in one of the early stages of the procedure, specifically in the "Training analysis and practical test" (point 3.4 of this work): As a general rule, the articles that respond to the search carried out in the specialised databases have not likely been analysed in the light of their original approaches, since those questions were not addressed explicitly or implicitly in most of the texts in the original sample.

This point, from a methodological point of view, posed a problem when making the planned review and even forced a new sampling, suggesting in the first place that the epistemology, the psychological approach, the didactic approach and the technoeducational implementation are not themes that occupy the authors of educational technology focused on the personalisation of learning.

Although the data shows a reality that is not surprising to researchers (Friesen \& Hug, 2009, among others; Selwyn, 2016; Williamson, 2013), it is once again essential to highlight this apparent disaffection of research -specially in Higher Education experiences- towards technologies for the instruction of the most basic approaches and foundations around education. Moreover, if we take into account that the sample includes not only 
articles that speak about the subject but also those that have an impact on subsequent publications, it means that for the rest of the researchers that use these references as a basis for their new discourses, such approaches are not important, or are not taken into account.

The relevant questions, at least from our point of view, are: what do they really talk about? what are the issues in the literature of educational technology? how can educational models be articulated around studies on the educational implementation of technologies that avoid raising the subject of education? do we understand educational technology as an issue independent of the pedagogical assumptions that underpin educational action? how this reality define our Higher Education model?

As the data shows, it is not evident that in these years we are clear whether we are talking about personalisation, adaptation and automation of educational processes, or mere responsivisation of environments (Bulger, 2016). We do not know either for who or for what that adaptation or personalisation is useful. Although there are periodic articles that proclaim the educator as the centre of the process, it is not necessarily related to adaptive learning but to other important aspects of the formative process.

As far as we know, it should be said that if the personalisation of learning (and teaching) is an "unavoidable challenge" to education today (Coll, 2016), it does not seem that some kinds of educational technology try to include pedagogy or educational foundations in the scene of that challenge. And if this is the case, how long is it possible to keep avoiding pedagogy and continue talking about education?

Authors' contributions

All authors have approved the manuscript for submission.

Authors' information

Linda Castañedais Educationalist and holds a ph.D. in Educational Technology. Dr. Castañeda is an Associate Professor in the Department of Didactics and School Organization at the Faculty of Education at the University of Murcia. She is a full member of the Group of Research in Educational Technology (GITE) at the same university. Her research and teaching is focussed on the implementation and impact of technologies in the educational (teaching and learning) models, processes and practices. Information about Linda's publications and work would be founded on her personal website http://www.lindacastaneda.com

Jordi Adell is an educationalist and holds a Ph.D. In Philosophy and Educational Sciences. Is Associate Professor in the Department on Education at the University Jaume I. Dr. Adell is the Director of the Center of Education and New Technologies at the same university and his research is focussed on the impact of technologies in the educational processes. More information about his work would be founded on his website http://elbonia.cent.uji.es/jordi Antonio Bartolome holds a Ph.D. In Philosophy and Educational Sciences. He is professor of Educational Technology and the director of the Institute of Research in Education at the University of Barcelona. He has coordinated several European Projects at H2020, former framwork programs and other calls. He is author of 30 books and more than 100 articles. His speciality is the design and development of Multimedia Educational resources. More information at: http:// www.Imi.ub.edu/personal/bartolome/

Competing interests

The authors declare that they have no competing interests.

\section{Publisher's Note}

Springer Nature remains neutral with regard to jurisdictional claims in published maps and institutional affiliations.

\section{Author details}

${ }^{1}$ Institute of Research in Education, Universitat de Barcelona, Pg. Vall d'Hebrón, 171, 08035 Barcelona, Spain. ${ }^{2}$ Grupo de Investigación de Tecnología Educativa, Departamento de Didáctica y Organización Escolar, Facultad de Educación, Universidad de Murcia, 30100 Murcia, Spain. ${ }^{3}$ Centre d'Educació i Noves Tecnologies CENT, Universitat Jaume I, 12071 Castellón de la Plana, Spain. 
Received: 8 August 2017 Accepted: 30 January 2018

Published online: 02 April 2018

\section{References}

Alheit, P. (1994) The 'biographical question' as a challenge to adult education. International Review of Education 40 (35):283-298

Anderson, L. W. (2005). Taxonomy Academy Handbook. The Taxonomy Academy. Anderson Research Group.

Anderson, L. W., \& Krathwohl, D. R. (2001). A taxonomy for learning, teaching, and assessing: a revision of Bloom's taxonomy of educational objectives. New York: Addison Wesley Longman.

Audi, R. (2011). Epistemology: a contemporary introduction to the theory of knowledge. New York: Routledge.

Castañeda, L. (2011) Analizar y entender la enseñanza flexible. Un modelo de análisis de desarrollo curricular. Píxel-Bit. Revista de Medios y Educación, 39, 167-195

Chih-Ming Chen, (2008) Intelligent web-based learning system with personalized learning path guidance. Computers \& Education 51 (2):787-814.

Cobo, C. (2016). La Innovación Pendiente.: Reflexiones (y Provocaciones) sobre educación, tecnología y conocimiento. Montevideo: Penguin Random House.

Bartolomé, A. (1994). Sistemas Multimedia. En Sancho, J. (1994). Para una tecnología Educativa (pp. 193-220). Barcelona: Horsori.

Beethan, H., \& Sharpe, R. (2007). Rethinking pedagogy for a digital age: designing for 21st century learning. New York: Routhledge.

Bloom, B. S. (1984). The 2 sigma problem: the search for methods of group instruction as effective as one-to-one tutoring. Educational Researcher, 13(6), 4-16.

Bloom, B. S., Engelgart, M. D., Furst, E. J., Hill, W. H. Y., \& Krathwohl, D. R. (Eds.) (1956). Taxonomy of educational objectives: the classification of educational goals. Handbook I: cognitive domain. New York: David McKay.

Bulger, M. (2016). Personalized learning: the conversations we're not having. Data and society working paper. Recuperado a partir de https://www.datasociety.net/pubs/ecl/PersonalizedLearning_primer_2016.pdf.

Carlson, H. L. (1991). Learning style and program design in interactive multimedia. Educational Technology Research and Development, 39(3), 41-48.

Coll, C. (2016). La personalització de l'aprenentatge escolar: un repte indefugible. In J. M. En Vilalta (Ed.), Reptes de l'educació a Catalunya. Anuari 2015. Barcelona: Fundació Faume Bofill ISBN: 978-84-945264-8-0. http://www.fbofill. cat/sites/default/files/RepteseducacioCatalunya.Anuari2015_041016.pdf.

Conole, G. \& Fill, K., (2005). A learning design toolkit to create pedagogically effective learning activities. Journal of Interactive Media in Education. 2005(1), 1-16. https://doi.org/10.5334/2005-8

Dede, C. (2008). Theoretical perspectives influencing the use of information technology in teaching and learning. In J. Voogt, \& G. Knezek (Eds.), International handbook of information technology in primary and secondary education. New York: Springer. https://doi.org/10.1007/978-0-387-73315-9_60.

Driscoll, M. P. (2005). Psychology of learning for instruction, (3rd ed., ). New York: Allyn \& Bacon.

Duchastel, Ph. (1986). Intelligent computer assisted instruction systems: the nature of learner control.

Engeström, Y. (1987). Learning by Expanding. An Activity-theoretical approach to developmental research. New York: Cambridge University Press.

Ertmer, P. A., \& Newby, T. J. (1993). Behaviorism, cognitivism, constructivism: comparing critical features from a design perspective. Performance Improvement Quarterly, 6(4), 50-72.

Friesen, N., \& Hug, T. (2009). The mediatic turn: exploring concepts for media pedagogy. In K. Lundby (Ed.), Mediatization: concept, changes, consequences, (pp. 63-83). New York: Peter Lang Publishing.

Fry, E. B. (1966). Máquinas de enseñar y enseñanza programada. Madrid: Magisterio Español.

Gayeski, D. M. (1995). Interactive toolkit. Itahca (NY): OmniCom Associates.

Gillespie, F. (2002). Instructional design for the new technologies. New Directions for Teaching and Learning, 76. https:// doi.org/10.1002/tl.7603.

Holma, K., \& Hyytinen, H. (2015). The philosophy of personal epistemology. Theory and Research in Education, 13(3), $334-350$.

Hudson, K. (1984). Introducing CAL: a practical guide to writing computer-assisted learning programs. London: Chapman \& Hall.

Hung, D. (2001). Theories of learning and computer-mediated instructional technologies. Educational Media International, 38(4), 281-287. https://doi.org/10.1080/09523980110105114.

Illeris, K. (2009). A comprehensive understanding of human learning. In K. Illeris (Ed.), Contemporary theories of learning: learning theorists ... in their own words, (pp. 7-20). London: Routledge.

Johnson, L., Adams Becker, S., Cummins, M., Estrada, V., Freeman, A., \& Hall, C. (2016). NMC horizon report: 2016 higher education edition. Austin, Texas: The New Media Consortium.

Kemp, J. E., \& Smellie, D. C. (1989). Planning, producing and using instructional media. New York: Harper \& Row.

Klotz, G. (1971). La enseñanza programada. Barcelona: Redondo.

Larkin, J., \& Chabay, R. (Eds.) (1992). Computer-assisted instruction and intelligent tutoring systems: shared goals and complementary approaches, Technology in Education Series (). Hillsdale (NJ): Lawrence Erlbaum Associates.

Lumsdaine, A. A., \& Glaser, R. (Eds.) (1960). Teaching machines and programmed learning: a source book. Oxford: National Education Association.

Martínez, F. (2001). El profesorado ante las Nuevas Tecnologías. In F. Blazquez (Ed.) Sociedad de la Información y Educación, pp. 193-215. Badajoz: Junta de Extremadura.

Marzano, R. (1998): What are the general skills of thinking and reasoning and how do you teach them?. Clearing House 71 (5). 268-273.

Marzano, R. (2001). Designing a new taxonomy of educational objectives. In T. R. Guskey, \& R. Marzano (Eds.), Experts in assessment series. Thousand Oaks, CA: Orwin Press. 
Marzano, R. J., Brandt, R.S., Hughes, C.S., Jones, B.F., Pressein, B., Rankin, S \& Suhor, C. (1988). Dimensions of thinking: A framework for curriculum and instruction. Alexandria: The Association for Supervision and Curriculum Development.

Marzano, R., \& Kendall, J. (2007). The new taxonomy of educational objectives, (Segunda Edición ed., ). Thousand Oaks, CA: Orwin Press.

McMillan, J. H., \& Schumacher, S. (2010). Research in education: evidence-based inquiry. Essex: Pearson Education Limited. Mezirow, J. (1991). Transformative dimensions of adult learning. San Francisco: Jossey-Bass.

Millward, R., Mazzucchelli, L., Magoon, S., \& Moore, R. (1978). Intelligent computer-assisted instruction. Behavior Research Methods \& Instrumentation, 10(2), 213-217. https://doi.org/10.3758/BF03205127.

Najjar, L. J. (1998). Principles of educational multimedia user interface design. Human Factors, 40(2), 311-323.

Okoli, C., \& Schabram, K. (2010). A guide to conducting a systematic literature review of information systems research. Sprouts: Working Papers on Information Systems, 10, 26.

Pane, J. F., Steiner, E. D., Baird, M. D., Hamilton, L. S., \& Pane, J. D. (2017). Informing progress: insights on personalized learning implementation and effects. Santa Monica, CA: RAND Corporation Available at www.rand.org/t/RR2042.

Puentedura, R. R. (2012). The SAMR model: background and exemplars (slides). Retrieved from http://www.hippasus. com/rrpweblog/archives/000073.html

Rogers, C.R. (1951). Client-centered Therapy: Its Current Practice, Implications, and Theory. Boston: Houghton Mifflin.

Rickel, J. W. (1989). Intelligent computer-aided instruction: a survey organized around system components. IEEE Transactions on Systems, Man and Cybernetics, 19(1), 40-57. https://doi.org/10.1109/21.24530.

Schwier, R. A., \& Misanchuk, E. R. (1993). Interactive multimedia instruction. Englewood Cliffs (NJ): Educational Technology Publications.

Selwyn, N. (2016). Is technology good for education? Cambridge: Polity Press.

Siemens, G. (2005). Connectivism. A learning theory for the digital age. International Journal of Instructional Technology and Distance Learning, 2(1), 3-10. Retrieved from: http://www.itdl.org/journal/jan_05/article01.htm

Skinner, B. F. (1965). The Technology of Teaching. Proceedings of the Royal Society of London. Series B, Biological Sciences, 162(989), 427-443 http://olms.cte.jhu.edu/olms2/data/resource/99656/Skinner\%20(1965).pdf.

Skinner, B. F. (1960). Teaching machines. The Review of Economics and Statistics, 42(3), 189-191 http://www.jstor.org/ stable/1926170

Skinner, B. F. (1979). Tecnología de la enseñanza. Barcelona: Labor

Snowden, D. J., \& Boone, M. E. (2007). A leader's framework for decision making. Harvard business review, 85(11), 68.

Taylor, R. (Ed.) (1980). The computer in the school: tutor, tool, tutee. New York: Teachers College Press.

Tomei, L. A. (2003). Challenges of teaching with technology across the curriculum: issues and solutions. London: Information Science Puyblishin.

U.S. Department of Education. (2017). Reimagining the role of technology in education: 2017 National Education Technology Plan update. U.S. Department of Education. Retrieved from https://tech.ed.gov/files/2017/01/HigherEd-NETP.pdf

Verhagen, P. (2006). Connectivism: a new learning theory. Journal of Educational Computing Research, 2(3), 379-393. https://doi.org/10.2190/D4JW-NR13-ADTA-MR8A.

Williamson, B. (2013). The future of the curriculum: school knowledge in the digital age. London: MA: The MIT Press.

Submit your manuscript to a SpringerOpen ${ }^{\circ}$ journal and benefit from:

- Convenient online submission

- Rigorous peer review

- Open access: articles freely available online

- High visibility within the field

- Retaining the copyright to your article

Submit your next manuscript at springeropen.com 